tribute to overcoming (either in diagnosis or therapy) a form of medicine in permanent scientific evolution. Through denial we will never understand the Complementary and Alternative Medicine phenomenon, and avoiding the debate will not cause our clients to refrain from turning to such practices. Complementary and Alternative Medicine exists and is part of our reality.

1. Luz MT. Cultura contemporânea e medicinas alternativas: novos paradigmas em saúde no fim do século XX. Physis 1997; 7:13-43.

2. Volich RM. Psicossomática - de Hipócrates à psicanálise. São Paulo: Casa do Psicólogo; 2000.

3. Silva MJP, Gimenes OMP. Eu - o cuidador. Mundo Saúde 2000; 24:306-9.

4. Silva MJP, Leão ER. Práticas complementares no alívio da dor. In: Leão ER, Chaves LD, organizadores. Dor - 5o sinal vital. Curitiba: Editora Maio; 2004. p. 121-34.

5. Capra F. O ponto de mutação. São Paulo: Cultrix; 1988.

\section{Andrea Caprara}

Mestrado em Saúde Pública Universidade Estadual

do Ceará, Fortaleza, Brasil. caprara@uece.br
The article by Barros \& Nunes discusses an interesting and timely subject regarding the multiple meanings of the terms Complementary and Alternative Medicine in Brazil. Numerous factors have converged in recent years and have sparked new and widespread interest in unconventional medicine. The authors respond to a question that is central to the subject regarding why physicians trained in allopathic practices opt to develop complementary forms of medicine. According to the results of their literature review, the desire to incorporate new therapeutic practices into the biomedical model helped create the concept of Complementary Medicine. In addition, the origin of the existing confusion of terms is the result of multiple meanings, for example between complementary tests and Complementary Medicine. I believe that the article answers the question only in part, and instead should explore at least two other fundamental reasons regarding: the historical aspects and the medical humanities 1 . I will address these two aspects making explicit reference to the biomedical literature.

Regarding the historical reasons, in the mid1970s, during preparations for the famous Conference of Alma Ata in 1978 organized by the World Health Organization (WHO) and United Nations Children's Fund (UNICEF), a decisive interest emerged in diverse forms of medicine throughout the world, listed in the official "Traditional Medicine" documents 2,3. The term "traditional" as used in the original documents of the time referred to healing practices connected with an ancient culture, antecedents to the formation of modern medicine 5 . But the term "traditional" was considered insufficient because it was used at the same time to describe complex curative models, like Ayurvedic medicine, and simple forms of self-healing 4 . The official Alma Ata documents recognized the need to reconsider traditional healers as providers of regular healthcare treatments and services. In fact, during those years interest in diverse forms of traditional medicine emerged from the WHO, principally in the effort to guarantee treatment coverage for all. Various research and training programs were launched, including traditional midwifery, also conducted in Brazil, involving numerous health professionals 5 . Their influence on the incorporation of complementary medicine into the biomedical model should not be underestimated.

Similar efforts have also been made by physicians and nurses involved in research and health services in the field of mental health, in the relationship with traditional healers, with indigenous health, and ethnobotany. Regarding the latter, various approaches are utilized concerning the commercial production, distribution, and conservation of plants to guarantee the quality and efficacy of therapeutic preparations. This issue poses problems for research ethics which could be called the creative rights to therapeutic practices. In various ways, ethnomedical research does not lead to true discovery, but confirms or disproves the efficacy of treatments used by various cultural groups; for example, often creative rights have been claimed by leaders of indigenous peoples in Latin America who regard the commercial gains made by Western society from the application of this indigenous knowledge as actual theft 6 . The concept of Complementary Medicine thus takes on different meanings according to the context in which it is considered: (1) in a medical facility in the West it can be the practice of aromatherapy used together with pharmacological therapy; (2) in an indigenous area it can be a therapy practiced by native healers in a health clinic; (3) in African culture, it can take the meaning reported in the experience by Henri Collomb and the Fann School.

The second aspect concerns the Medical Humanities. With the growing demand for healthcare throughout the West, dissatisfaction and disillusionment are increasing with regard to the quality of relationships with health system 
personnel and services in general. The growth of modern medicine should have been accompanied by the disappearance of (or at least a reduction in) Complementary Medicine 7. We are instead witnessing the opposite phenomenon, in which ever-wider portions of the population seek solutions to their ailments by turning to a burgeoning selection of alternative medical treatments 7 . The fragmentation of medical practice into a variety of specialties, the growing importance of instrumental and laboratory diagnostics to the detriment of clinical examination, and the growing bureaucratization of medical services have all undermined the physician-patient relationship ${ }^{8}$. In effect, we are dealing with a complex phenomenon and a rather heterogeneous array of services. What emerges is the fact that different forms of Alternative Medicine all seem to ensure, in the relationship between provider and patient, a notable capacity to listen, an emotional connection, and personalized involvement 9 . These characteristics undoubtedly act on the patient, favoring the expectation of recovery, where the possible positive effects should not be underestimated 8 . Thus, besides the notable heterogeneity of individual types of Alternative Medicine, it is these shared characteristics that somehow appear to build a common ground for the efficacy of these treatments as compared to Western medicine.

Finally, in the biomedical model, research advances in psychoneuroimmunology and new interpretive disease models require careful investigation of the entire phenomenon. These studies underline efficacy in terms of the relationship established by doctor and patient, the expectations for healing that these encounters produce, the therapeutic value of treatment (in terms of both the symbolic power and the active ingredients at work), and the social relationships 10 . Alternative therapeutic practices show that efficacy relates not only to the active ingredients at work but also to the symbolic value that the plant, animal, or mineral brings to bear in a specific cultural context. That is, it is a part of a wider, trans-disciplinary context, represented today by the medical humanities that introduce aspects of human sciences in training and medical practice belonging to various artistic expressions 11. I believe that all the elements described here should be taken into consideration by the authors so that they can respond in a more articulate and complete way to the question posed in the article.

1. Evans M, Greaves D. Exploring the medical humanities. BMJ 1999; 319:1216.

2. World Health Organization. Promotion et développment de la médecine traditionnelle. Rapport d'une réunion de l'OMS. Geneva: World Health Organization; 1978.

3. World Health Organization. Médecine traditionnelle et couverture des soins de santé. Textes choisis à l'intention des administrateurs de la santé. Geneva: World Health Organization; 1983.

4. Bannerman RH, Burton J, Wen-Chieh C. Traditional medicine and health care coverage: a reader for health administrators and practitioners. Geneva: World Health Organization; 1983.

5. Araujo G, Araujo L, Janowitz B, Wallace S, Potts M. Parteras tradicionales en la atención obstétrica del noreste de Brasil. Bol Oficina Sanit Panam 1984; 96:147-59.

6. Posey D. Intellectual property rights: what is the position of ethnobiology? Journal of Ethnobiology 1990; 10:93-8.

7. Le Fanu J. The rise and fall of modern medicine. London: Carroll \& Graf; 2000.

8. Seppilli T, Petrangeli E, Caprara A. Terapie non convenzionali: indagine descrittiva nella Regione Umbria, Italia. In: VII SINAPIH, Rio de Janeiro; 2002.

9. Luz M. A arte de curar e a ciência das doenças: história social da homeopatia no Brasil. Rio de Janeiro: Dynamis; 1996.

10. Kelner M, Wellman B. Complementary and alternative medicine: challenge and change. London: Routledge; 2000.

11. Kaye C, Blee T, editors. The arts in health care. London: Jessica Kingsley Publishers; 1997.

Russell Parry Scott

Centro de Filosofia e Ciências Humanas, Universidade Federal de Pernambuco, Recife, Brasil. scott@hotlink.com.br
One of the rich characteristics of "alternative" medicine is that it rebels against and resists classifications that involve exclusiveness and particularity. Yet it is precisely the need to see the forest rather than just the trees that motivates good synthesis studies. In this spirit of contribution, Barros \& Nunes present a brief overview of an argument on two concepts and different meanings. Their title announces the duality of concepts: Complementary and Alternative Medicine in Brazil: One Concept, Different Meanings. It is a useful effort that helps elucidate some sources of imprecision on a debate that currently displays so many interfaces that it appears to be primarily a festival of disagreements and miscellaneous positions. The article is particularly instigating because it shows a historical concern by many complementary and alternative authors with classifications that mark the borders between "the alternatives" as heteroclitic practices which alternate between seeking to sustain their difference and attempt- 